\title{
Monitoring Quality Loss of Pasteurized Skim Milk Using Visible and Short Wavelength Near-Infrared Spectroscopy and Multivariate Analysis
}

\author{
H. M. Al-Qadiri, ${ }^{\star 1}$ M. Lin, $†$ M. A. Al-Holy,‡ A. G. Cavinato,§ and B. A. Rasco\# \\ *Department of Nutrition and Food Technology, Faculty of Agriculture, University of Jordan, Amman 11942, Jordan \\ †Food Science Program, University of Missouri, Columbia 65211-5160 \\ fDepartment of Clinical Nutrition and Dietetics, Faculty of Allied Health Sciences, Hashemite University, Zarqa 13115, Jordan \\ $\S C h e m i s t r y$ and Biochemistry Program, Eastern Oregon University, One University Blvd., La Grande 97850-2899 \\ \#Department of Food Science and Human Nutrition, Box 646376, Washington State University, Pullman 99164-6376
}

\begin{abstract}
Visible and short wavelength near-infrared diffuse reflectance spectroscopy (600 to $1,100 \mathrm{~nm}$ ) was evaluated as a technique for detecting and monitoring spoilage of pasteurized skim milk at 3 storage temperatures $\left(6,21\right.$, and $37^{\circ} \mathrm{C}$ ) over 3 to $30 \mathrm{~h}$ (control, $t=0 \mathrm{~h} ; \mathrm{n}=3$ ). Spectra, total aerobic plate count, and $\mathrm{pH}$ were obtained, with a total of 60 spectra acquired per sample. Multivariate statistical procedures, including principal component analysis, soft independent modeling of class analogy, and partial least squares calibration models were developed for predicting the degree of milk spoilage. Principal component analysis showed apparent clustering and segregation of milk samples that were stored at different time intervals. Milk samples that were stored for $30 \mathrm{~h}$ or less at different temperatures were noticeably separated from control and distinctly clustered. Soft independent modeling of class analogy analysis could correctly classify 88 to $93 \%$ of spectra of incubated samples from control at $30 \mathrm{~h}$. A partial least squares model with 5 latent variables correlating spectral features with bacterial counts and $\mathrm{pH}$ yielded a correlation coefficient $(\mathrm{R}=0.99$ and 0.99$)$ and a standard error of prediction $\left(0.34 \log _{10} \mathrm{cfu} / \mathrm{mL}\right.$ and 0.031 $\mathrm{pH}$ unit), respectively. It may be feasible to use short wavelength near-infrared spectroscopy to detect and monitor milk spoilage rapidly and noninvasively by correlating changes in spectral features with the level of bacterial proliferation and milk spoilage.
\end{abstract}

Key words: short wavelength near-infrared, milk spoilage, pasteurization, spectroscopy

\section{INTRODUCTION}

A large number of microorganisms are identified as contaminants of milk drawn from healthy cows that

Received August 15, 2007.

Accepted November 8, 2007.

${ }^{1}$ Corresponding author: h.qadiri@ju.edu.jo cause deterioration of milk quality (Hayes et al., 2002). The udder canal and teat surface have their own microflora so that milk drawn aseptically from the cow is not sterile but contains micrococci, streptococci, and corynebacteria (Garbutt, 1997). Milk contains other bacterial contaminants from soil, water, animal feed and bedding, and animal feces. Those include gramnegative rods (Pseudomonas, Alcaligenes, Acinetobacter, and Flavobacterium), gram-positive bacteria (Bacillus, Clostridium, Listeria, and Staphylococcus), Enterobacteriaceae, lactic acid bacteria (Streptococcus, Lactococcus, Lactobacillus, and Leuconstoc), yeasts, and molds (Garbutt, 1997; Deeth et al., 2002; Giraffa, 2003).

Milk that is produced under good hygienic conditions may contain microbial numbers as low as $10^{3} \mathrm{cfu} / \mathrm{mL}$; however, under poor hygienic conditions, numbers may be as high as $10^{5} \mathrm{cfu} / \mathrm{mL}$ or even greater (Garbutt, 1997). Milk contains significant nutrients including lactose, AA, vitamins, nucleotides, inorganic salts, and trace elements that make milk an ideal growth medium for a wide range of pathogenic and spoilage microorganisms. Additionally, the high water activity (0.98) and neutral $\mathrm{pH}$ (6.6) provide very conductive conditions for rapid growth of a wide range of microorganisms.

Temperature has an important effect on milk quality by controlling the rate of microbial spoilage. Pasteurized milk held at high ambient temperatures spoils rapidly. Accordingly, milk storage under refrigeration temperature (2 to $4^{\circ} \mathrm{C}$ ) across the food supply chain is essential if a reasonable shelf life is to be ensured (Garbutt, 1997).

The pasteurization process kills the vegetative cells of human pathogens, viruses, and many gram-negative microorganisms that can cause raw milk to spoil. Postprocess recontamination with psychrotrophic bacteria may occur during filling, consumer handling, or due to the improperly cleaned pasteurizers (Gruetzmacher and Bradley, 1999; Hayes et al., 2002). Psychrotrophic gram-negative rods (particularly the genus Pseudomo- 
nas) are the most significant spoilage microbes in refrigerated pasteurized milk (Walker, 1988; Hayes et al., 2002). However, storage of pasteurized milk at high ambient temperatures is likely to result in souring via the activity of mesophilic microorganisms that survived the heat process or in milk putrefying due to the activity of psychrotrophic bacteria (e.g., Pseudomonas species) that recontaminate pasteurized milk (Garbutt, 1997; Hayes et al., 2002).

Infrared spectroscopy is a nondestructive technique. Spectral features provide biochemical information regarding the molecular composition and molecular structure of cells and tissues (including bacterial cells) as well as the nature and type of molecular interactions between different cells and tissues (Choo-Smith et al., 2001). Short wavelength near-infrared (SW-NIR) spectroscopy (600 to $1,100 \mathrm{~nm}$ ) is widely used in food analysis, recently for quantitative detection of the microbial spoilage in chicken meat (Lin et al., 2004), for detection of spoilage in rainbow trout fillets (Lin et al., 2006) and quality management of beef and meat products (Ellis et al., 2002; Liu et al., 2003). Short wavelength nearinfrared spectroscopy is also an effective technique for noninvasive measurement of food constituents such as lipid (Lee et al., 1992), protein, and certain carbohydrates and various quality features (such as color, cell structure, and internal bruising) in agricultural products and food-related industries. Accordingly, SW-NIR spectroscopy can be used in food quality control to monitor food safety, spoilage, and quality by acquiring metabolic snapshots and providing either a qualitative or quantitative estimate of the microbial load on a food sample. The main objective of this study was to evaluate the feasibility of using visible and SW-NIR spectroscopy (600 to 1,100 nm) to develop a rapid, noninvasive procedure for monitoring the spoilage of pasteurized skim milk that could be used in industrial or retail settings.

\section{MATERIALS AND METHODS}

\section{Milk Sample Preparation}

Pasteurized skim milk (1-L container, $0.2 \%$ fat) was obtained from a local grocery refrigerated case and transported on ice to the laboratory the day the experiment was conducted. To examine the microbial quality of purchased skim milk, total aerobic plate count (APC) and $\mathrm{pH}$ measurements were carried out in triplicate. Milk was aseptically transferred to 20 -mL sterile covered beakers and held at 6,21 , or $37^{\circ} \mathrm{C}$ for $t=0,3,8$, or $30 \mathrm{~h}(\mathrm{n}=3)$.

\section{Microbial Analysis and pH Measurement}

Milk samples were tested at each storage temperature and time interval in triplicate manner for total
APC and pH. For APC, 10-fold serial dilutions of the milk were prepared in $0.1 \%$ peptone water, and a spread plate method $(0.1 \mathrm{~mL})$ was performed (Lopez-Fandino et al., 1996) using tryptic soy agar (Difco, Sparks, MD). The plates were incubated for $48 \mathrm{~h}$ at $28^{\circ} \mathrm{C}$. The APC was enumerated as base-10 logarithm (cfu) per milliliter and served as a reference value in the partial least squares (PLS) models. The $\mathrm{pH}$ measurement of milk samples was recorded at each time interval to 0.01 units ( $\mathrm{pH}$ meter AB15, Fisher Scientific Company, Pittsburgh, PA).

\section{Spectra Collection}

Visible and SW-NIR spectra of a milk sample were acquired using DPA-20 spectrophotometer (D-Squared Development Inc., La Grande, OR) for the control (0 h) and at each storage period. The spectrophotometer probe consists of 32 illumination fibers $(600 \mu \mathrm{m}$ in diameter) arranged in a concentric circle that was $2 \mathrm{~mm}$ away from a central single pick-up fiber (Lin et al., 2006). Before spectral acquisition of milk samples, a dark and a reference spectrum of Spectralon (Labsphere Inc., North Sutton, NH) were acquired. Spectralon is a thermoplastic resin with high reflectance behavior in the near-infrared region (Lin et al., 2006). Spectralon was immersed to the milk samples to reflect SW-NIR light back to the pick-up fiber. Accordingly, the reference spectrum was automatically subtracted from the sample spectrum by the instrument in each measurement.

Each sample of $20 \mathrm{~mL}$ of pasteurized skim milk was poured into a preautoclaved $100-\mathrm{mL}$ beaker. The probe was wiped and sanitized with $70 \%$ ethanol and then inserted directly into milk samples. Spectra were collected in the diffuse reflectance mode over a wavelength range from 600 to $1,100 \mathrm{~nm}$ at $0.5-\mathrm{nm}$ intervals. Triplicate samples were examined for each storage period with 20 spectra acquired at different locations within each sample (yielding a total of 60 spectra per sample). An individual spectrum was the average of 60 scans with a 200-ms exposure time for each scan. Sample spectra were obtained at the same temperature $\left(\sim 22^{\circ} \mathrm{C}\right)$ for all samples to control for spectral changes that could result from temperature differences during spectral collection. In addition, to reduce the effect of milk curdling on spectral patterns, each sample was aseptically mixed before spectra collection (milk curdling was expected due to the coagulation of milk protein at lower $\mathrm{pH}$ values for samples held for longer periods at the higher storage temperatures).

\section{Data Analysis}

Delight version 3.2.1 (Textron Systems, Wilmington, MA) software was used to conduct data analysis. Data 
Table 1. The mean aerobic plate count $\left(\log _{10} \mathrm{cfu} / \mathrm{mL}\right)$ and the mean $\mathrm{pH}$ measurement for milk samples at each storage period

\begin{tabular}{|c|c|c|c|c|c|c|c|c|c|c|}
\hline \multirow[b]{2}{*}{ Item } & \multirow{2}{*}{$\frac{\text { Control }}{0 \mathrm{~h}}$} & \multicolumn{3}{|c|}{$6^{\circ} \mathrm{C}$} & \multicolumn{3}{|c|}{$21^{\circ} \mathrm{C}$} & \multicolumn{3}{|c|}{$37^{\circ} \mathrm{C}$} \\
\hline & & $3 \mathrm{~h}$ & $8 \mathrm{~h}$ & $30 \mathrm{~h}$ & $3 \mathrm{~h}$ & $8 \mathrm{~h}$ & $30 \mathrm{~h}$ & $3 \mathrm{~h}$ & $8 \mathrm{~h}$ & $30 \mathrm{~h}$ \\
\hline $\log _{10} \mathrm{cfu} / \mathrm{mL}^{1}$ & 2.7 & 2.9 & 3.0 & 3.7 & 3.0 & 4.2 & 8.7 & 4.6 & 6.0 & 10.5 \\
\hline $\mathrm{pH}^{2}$ & 6.66 & 6.64 & 6.62 & 6.58 & 6.54 & 6.46 & 6.27 & 6.47 & 6.10 & 5.43 \\
\hline
\end{tabular}

preprocessing algorithms including binning, smoothing, and second-derivative transformation were performed to reduce spectral features overlapping (Huang et al., 2002). Spectral data were first binned by $2 \mathrm{~cm}^{-1}$ and smoothed with a Gaussian function of 15 $\mathrm{cm}^{-1}$ and then followed by a second-derivative transformation of $15 \mathrm{~cm}^{-1}$ gap (Lin et al., 2003; Al-Qadiri et al., 2006).

Multivariate statistical analysis procedures were performed to analyze data. Spectral data were statistically analyzed by principal component analysis (PCA), soft independent modeling of class analogy (SIMCA), and PLS regression (Oust et al., 2004; Rodriguez-Saona et al., 2004). Principal component analysis provides graphical representations of similarities and differences in spectral data between treatments (Martens and Naes, 1989; Goodacre et al., 1998; Kansiz et al., 1999) by removing random variation and generating natural clustering within a data set (Rodriguez-Saona et al., 2001; Nilsen et al., 2002). The first principal component (PC1) expresses the largest amount of spectral variation followed by the second principal component (PC2), which explains the largest part of remaining spectral variation, and so on (Rodriguez-Saona et al., 2004). Soft independent modeling of class analogy classifies samples according to their degree of analogy to the training samples (Hampton et al., 2001-2002; Al-Holy et al., 2006). Partial least squares is widely used to establish a calibration model and to provide a correlation between reference data (actual values measured by a primary technique) with SW-NIR spectral data (predicted values; Lin et al., 2003; Oust et al., 2004). The standard error of prediction (SEP) was calculated to identify the predictive performance of the PLS calibration models (Lin et al., 2003):

$$
S E P=\sqrt{\frac{\sum_{i=1}^{n}(X-Y)^{2}}{n-1}}
$$

where $X=$ the measured bacterial count; $Y=$ the predicted bacterial count; and $n=$ the number of samples.

\section{RESULTS AND DISCUSSION}

The mean base-10 logarithm APC and the mean $\mathrm{pH}$ measurement for control milk samples $(t=0 \mathrm{~h})$ were $2.7 \log _{10} \mathrm{cfu} / \mathrm{mL}$ and 6.66 , respectively (Table 1 ). There was no significant increase in APC or obvious decrease in $\mathrm{pH}$ for milk samples stored at $6^{\circ} \mathrm{C}$ even after $30 \mathrm{~h}$ of storage. However, results showed a significant increase in APC and a relatively distinct decrease in $\mathrm{pH}$ during the storage at 21 and $37^{\circ} \mathrm{C}$ over 8 to $30 \mathrm{~h}$, which is caused by the growth of bacterial cells (Table 1 ).

Representative visible and SW-NIR spectra (600 to $1,100 \mathrm{~nm}$ ) of control and incubated milk samples stored at 6,21 , and $37^{\circ} \mathrm{C}$ for $t=3,8$, and $30 \mathrm{~h}$ are shown in Figure 1. The absorption peaks of water band are mainly due to the $2 \rho_{1}+\rho_{3}$ overtone combination transition band of the $\mathrm{O}-\mathrm{H}$ stretching and bending mode around $960 \mathrm{~nm}$, where $\rho_{1}=$ the symmetric $\mathrm{O}-\mathrm{H}$ stretch;

Table 2. Soft independent modeling of class analogy classification results of each storage treatment compared with the other test treatments regarding storage temperature at $t=3,8$, and $30 \mathrm{~h}$

\begin{tabular}{|c|c|c|c|c|c|c|}
\hline \multirow[b]{3}{*}{ Storage treatment } & \multicolumn{6}{|c|}{ Correctly classified spectra } \\
\hline & \multicolumn{2}{|c|}{$3 \mathrm{~h}$} & \multicolumn{2}{|c|}{$8 \mathrm{~h}$} & \multicolumn{2}{|c|}{$30 \mathrm{~h}$} \\
\hline & $\mathrm{n}$ & $\%$ & $\mathrm{n}$ & $\%$ & $\mathrm{n}$ & $\%$ \\
\hline Control (0 h) & 49 & 82 & 54 & 90 & 55 & 92 \\
\hline $6^{\circ} \mathrm{C}$ & 50 & 83 & 53 & 88 & 56 & 93 \\
\hline $21^{\circ} \mathrm{C}$ & 51 & 85 & 52 & 87 & 53 & 88 \\
\hline $37^{\circ} \mathrm{C}$ & 54 & 90 & 53 & 88 & 55 & 92 \\
\hline
\end{tabular}


A

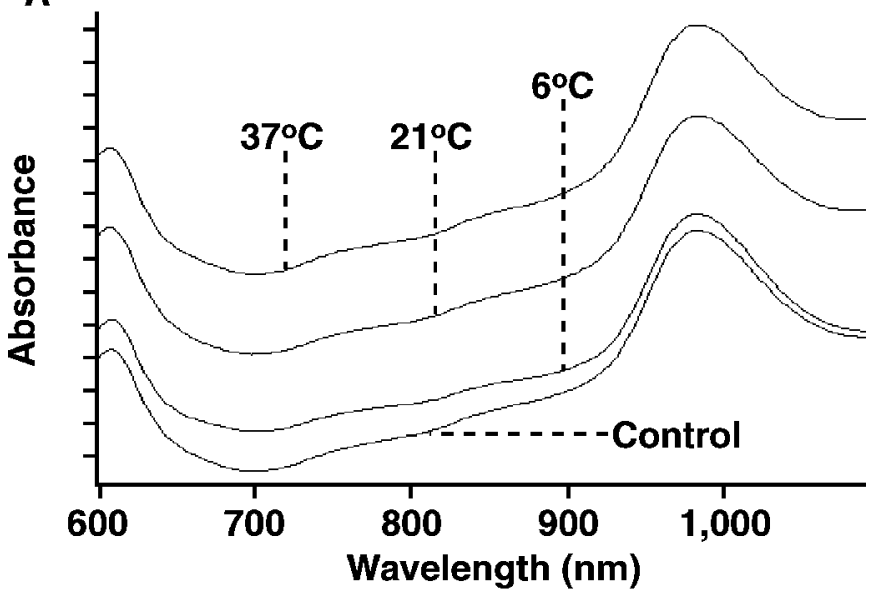

B
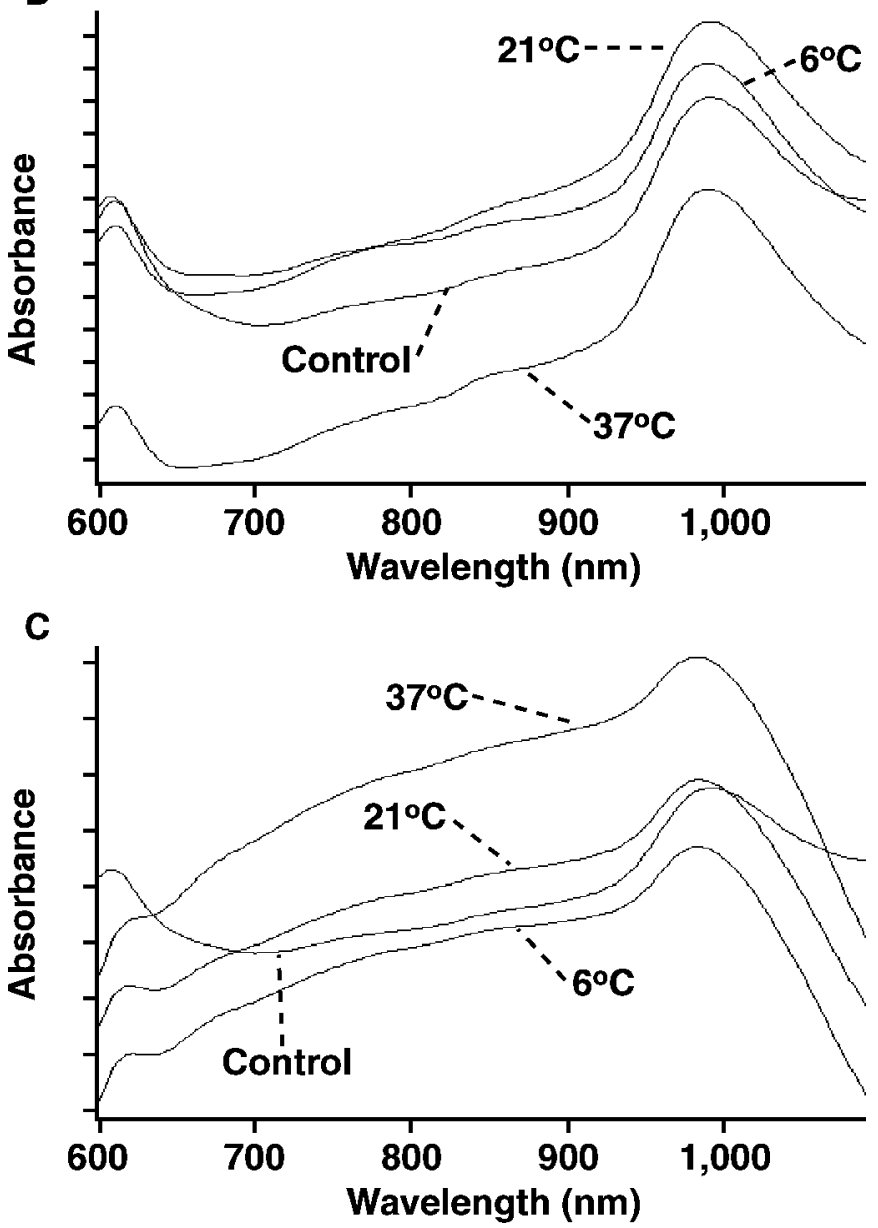

Figure 1. Representative visible and short wavelength near-infrared spectral patterns (600 to $1,100 \mathrm{~nm})$ of control $(t=0 \mathrm{~h})$ and milk samples stored at 6,21 , and $37^{\circ} \mathrm{C}$ for $t=3(\mathrm{~A}), 8(\mathrm{~B})$, and $30 \mathrm{~h}(\mathrm{C})$.
A
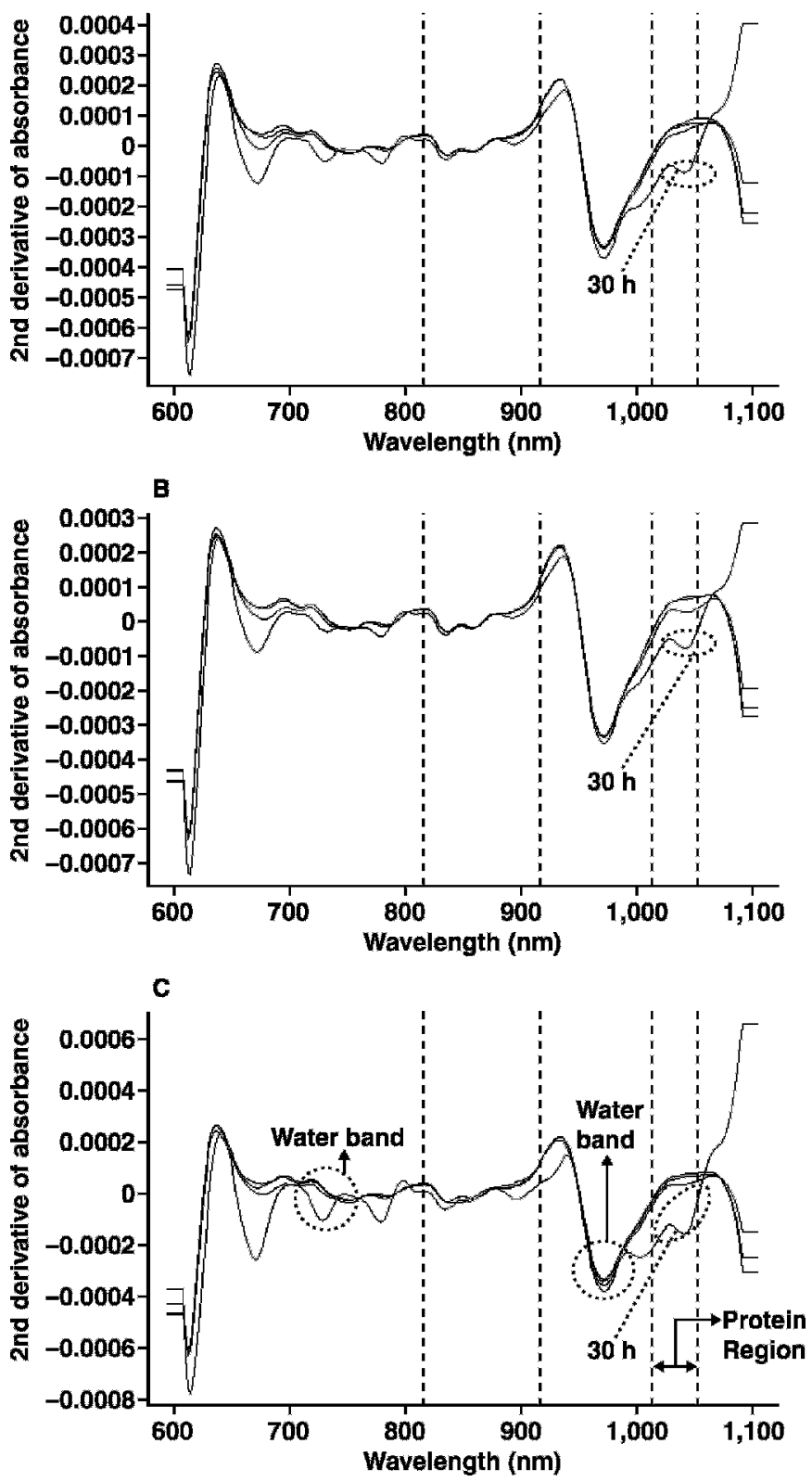

Figure 2. Representative second-derivative transformation of spectral patterns for control $(t=0 \mathrm{~h})$ and milk samples stored at 6 (A), $21(\mathrm{~B})$, and $37^{\circ} \mathrm{C}(\mathrm{C})$ for $t=3,8$, and $30 \mathrm{~h}$.

$\rho_{3}=$ the asymmetric $\mathrm{O}-\mathrm{H}$ stretch; and $\rho_{2}=$ the $\mathrm{O}-\mathrm{H}$ binding mode (Lee et al., 1992; Lin et al., 2004).

There are apparent variations among the spectral patterns at different storage times and temperatures (Figure 1); however, it is difficult to study the variations in spectral patterns by examining raw absorption data (Al-Qadiri et al., 2006). Therefore, data preprocessing algorithms were used to amplify spectral variations, with binning, smoothing, and normalization conducted 

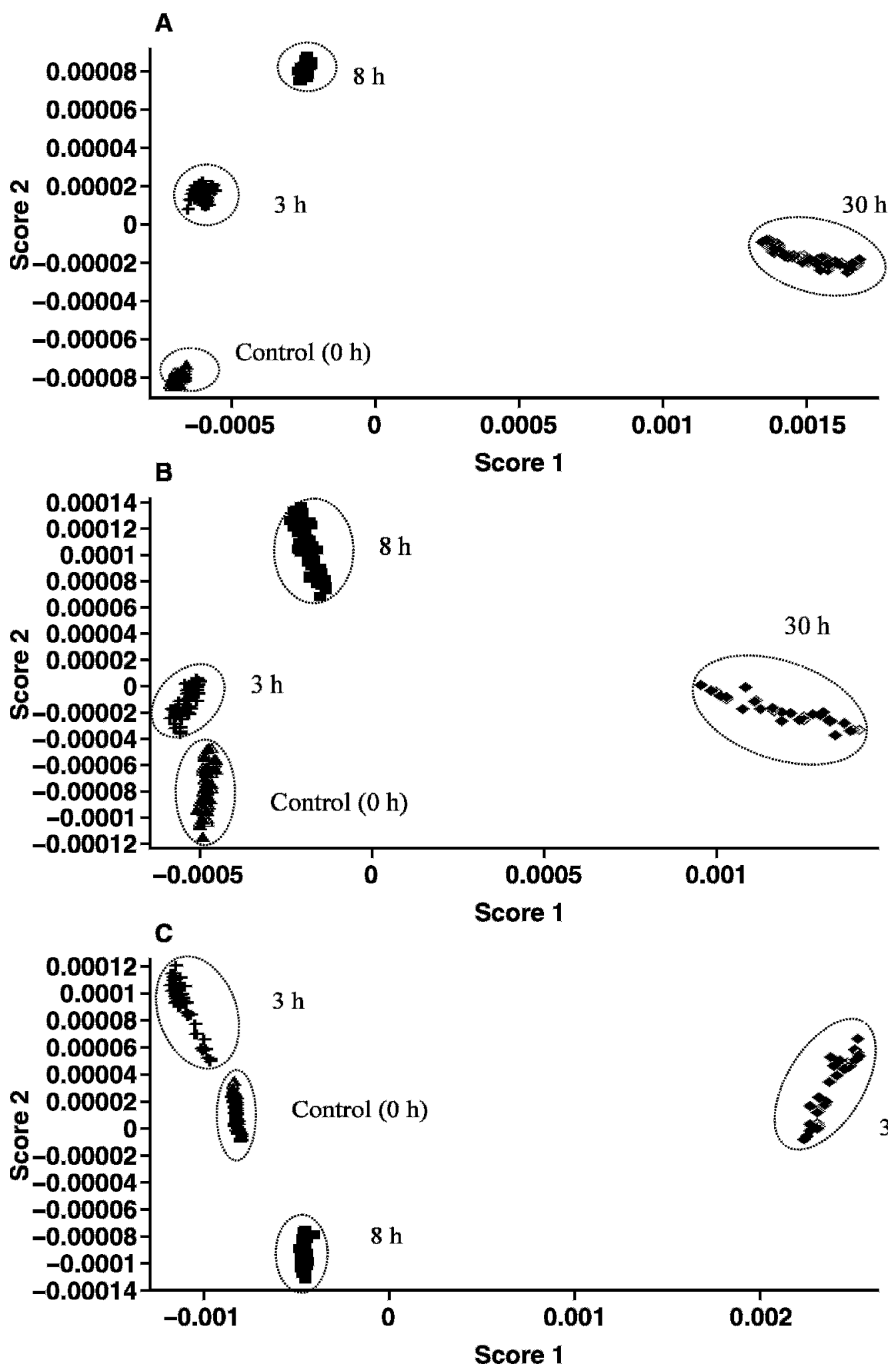

Figure 3. Principal components analysis for control $(t=0 \mathrm{~h})$ and pasteurized milk samples stored at $6(\mathrm{~A}), 21(\mathrm{~B})$, and $37^{\circ} \mathrm{C}(\mathrm{C})$ for $t=$ 3,8 , and $30 \mathrm{~h}$. 


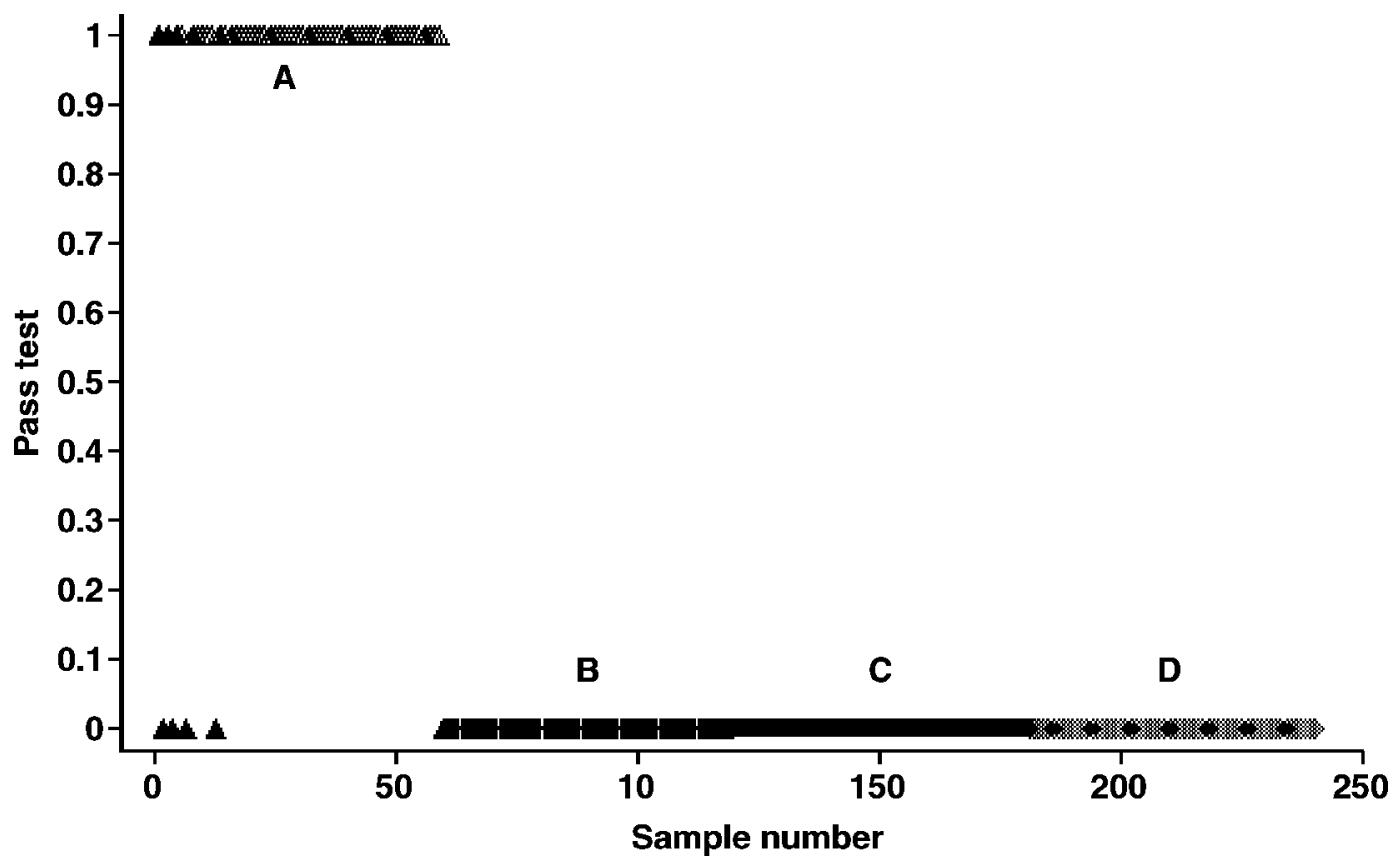

Figure 4. Soft independent modeling of class analogy classification of control ( $t=0 \mathrm{~h}$; A) compared with milk samples stored at 6 (B), 21 (C), and $37^{\circ} \mathrm{C}(\mathrm{D})$ at $t=30 \mathrm{~h}$.

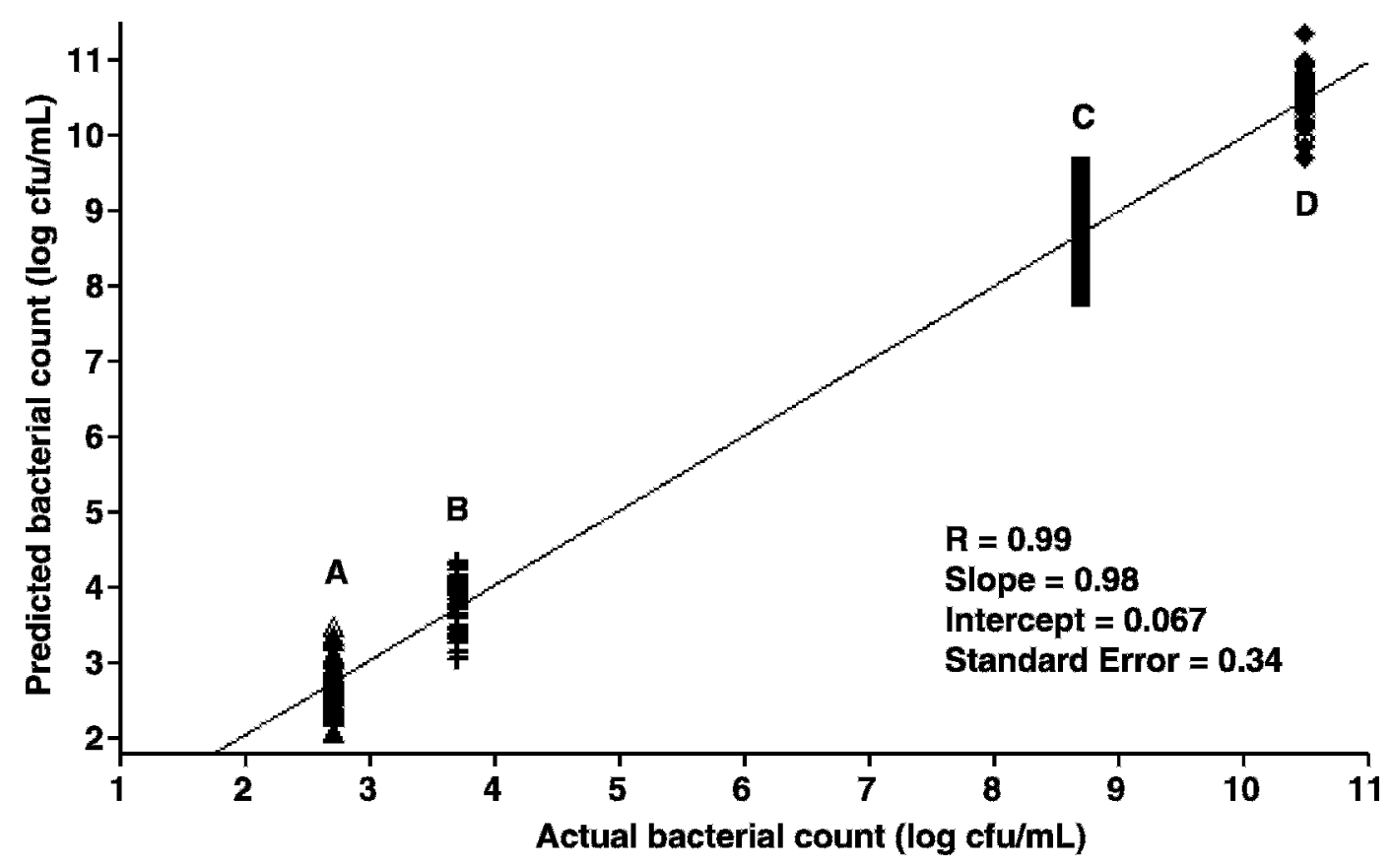

Figure 5. Comparison of the measured with predicted bacterial count $\left(\log _{10}\right.$ aerobic plate count cfu/mL) for a partial least squares model (5 latent variables): control ( $t=0 \mathrm{~h} ; \mathrm{A})$ and milk samples stored at $6(\mathrm{~B}), 21(\mathrm{C})$, and $37^{\circ} \mathrm{C}(\mathrm{D})$ for $t=30 \mathrm{~h}$. 


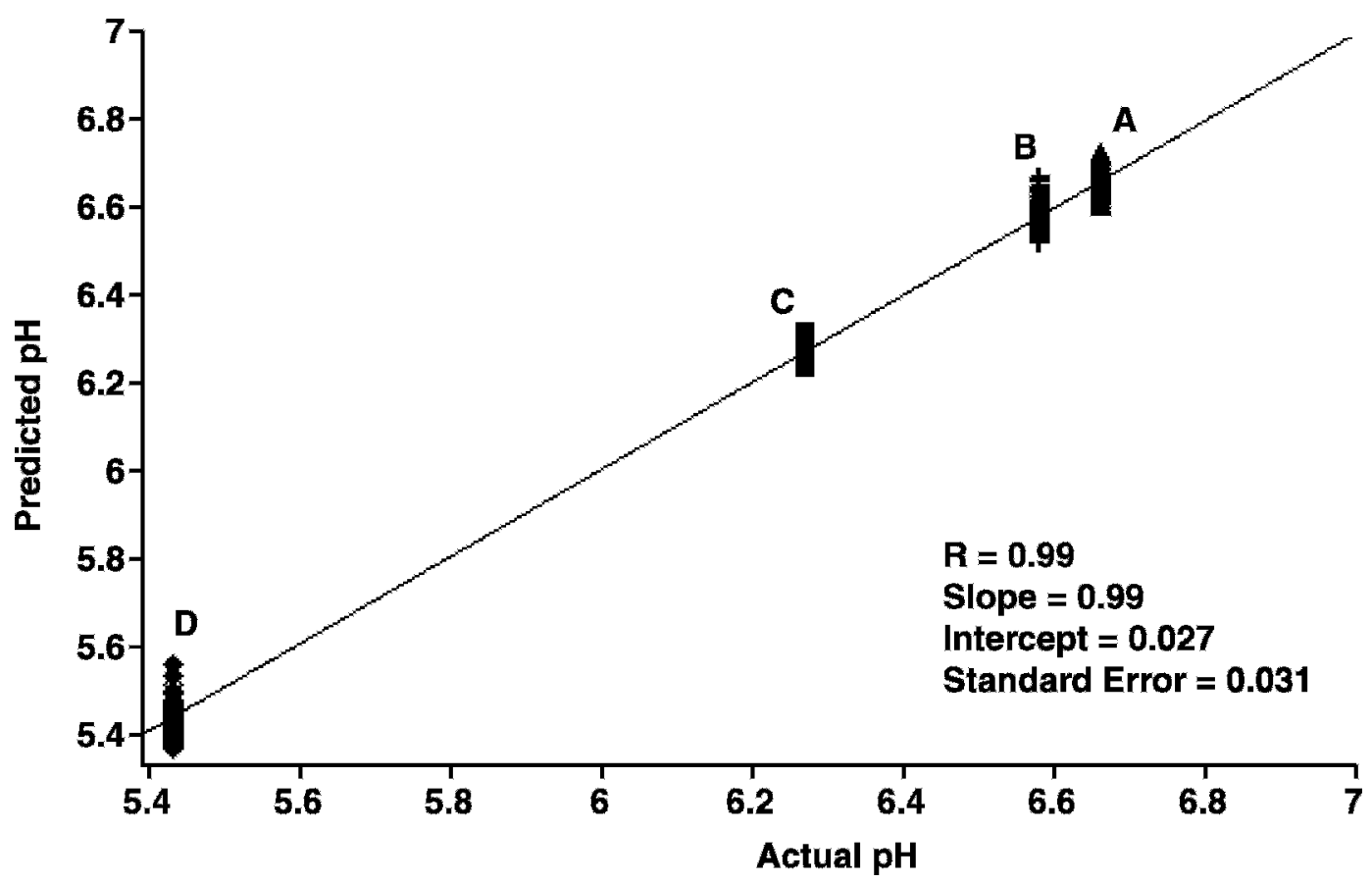

Figure 6. Comparison of the measured and predicted $\mathrm{pH}$ for a partial least squares model (5 latent variables): control $(t=0 \mathrm{~h}$; A) and milk samples stored at $6(\mathrm{~B}), 21(\mathrm{C})$, and $37^{\circ} \mathrm{C}(\mathrm{D})$ for $t=30 \mathrm{~h}$.

to decrease the overlap of spectral features and to eliminate high-frequency instrumental noise and baseline shifts (Lin et al., 2003; Liu et al., 2003; Al-Qadiri et al., 2006).

Second-derivative transformation was conducted to separate overlapping bands, reduce the variability between replicate spectra due to baseline offsets, and generate an estimate of the number of overlapped bands within a specific spectral region (Lee et al., 1992; Al-Qadiri et al., 2006). Spectral derivatization enhances the clarity of spectral features and improves apparent spectral resolution.

A representative second-derivative transformation (15-point second-order derivatization) of spectra for control $(t=0 \mathrm{~h})$ and incubated milk samples stored at 6,21 , and $37^{\circ} \mathrm{C}$ for $t=3,8$, and $30 \mathrm{~h}$ is shown in Figure 2 . The variation among spectral patterns between the different treatments become more distinctive with spectral differences apparent in the protein region as a result of proteolytic reactions; with possible band assignments of $\mathrm{RNH}_{2}$ around 1,014 and $1,031 \mathrm{~nm}$ and $\mathrm{NH}$ around $1,030 \mathrm{~nm}$ (Osborne and Fearn, 1986). Spectral variations at 744 and $960 \mathrm{~nm}$ can be assigned to $\mathrm{OH}$ of water and are also indicative of proteolysis. The spectral variations were significantly apparent in samples that were stored at $37^{\circ} \mathrm{C}$ for $30 \mathrm{~h}$ due to the high degree of spoilage and the rapid spoilage rate at elevated temperatures.
To differentiate between storage treatments, multivariate statistical analysis procedures (PCA, SIMCA, and PLS) were applied based upon variations in the spectral patterns. Principal component analysis is widely used to explain spectral data differences, capture-related variations, and cluster samples depending upon variations in the spectral patterns that are associated with the degree of milk spoilage (Lin et al., 2003). A mean-centered PCA (Figure 3) was carried out on the second-derivative SW-NIR spectra over the range of 600 to $1,100 \mathrm{~nm}$. The 2-dimensional PCA clustering results from SW-NIR spectra at different temperatures and times of storage demonstrated very distinct clustering and segregation between treatments. This indicates the feasibility of using visible and SW-NIR spectroscopy to discern variations in the biochemical changes and the level of deterioration resulting from proteolysis and lipolysis that result from bacterial activity that causes milk spoilage.

Soft independent modeling of class analogy analysis was performed to determine if samples from the various treatments could be classified based upon models developed for storage treatments at different temperature values and assigned to a class based upon the degree of analogy. According to SIMCA classification results (Figure 4) of control ( $t=0 \mathrm{~h}$ ) compared with the other storage treatments regarding storage temperature for $t=30 \mathrm{~h}, 55$ out of 60 spectra $(92 \%)$ of 
control were correctly classified. Table 2 shows SIMCA classification results of each storage treatment compared with the other test treatments regarding storage temperature at $t=3,8$, and $30 \mathrm{~h}$.

Partial least squares was used to establish a calibration model and provide a correlation between reference data (measured values) with SW-NIR spectral data (predicted values). Accordingly, a PLS prediction model was developed to quantify the bacterial counts (APC $\log _{10} \mathrm{cfu} / \mathrm{mL}$; Figure 5) and $\mathrm{pH}$ values (Figure 6) in milk samples at different storage periods, for example $t=30 \mathrm{~h}$. Validation results of the PLS model with 5 latent variables for predicting the bacterial counts and $\mathrm{pH}$ values yielded a correlation coefficient $(R=0.99$ and 0.99$)$ and a SEP $\left(0.34 \log _{10} \mathrm{cfu} / \mathrm{mL}\right.$ and $0.031 \mathrm{pH}$ unit), respectively, indicating that an accurate quantification of microbial counts and $\mathrm{pH}$ values in milk samples can be determined from a PLS-based prediction method.

\section{CONCLUSIONS}

The formation of metabolic by-products, proteolysis, and lipolysis caused by bacterial cell growth leads to a reduction in $\mathrm{pH}$ and undesirable biochemical changes. These changes can be detected by visible and SW-NIR diffuse spectroscopy (600 to $1,100 \mathrm{~nm}$ ) to differentiate wholesome and spoiled milk samples without the necessity of enumerating bacteria. Multivariate data analytical techniques such as PCA could segregate storage treatments $\left(6\right.$ to $37^{\circ} \mathrm{C}$ storage for 0 to $30 \mathrm{~h}$ ) with approximately $90 \%$ accuracy. Accurate quantification of microbial counts $\left(\mathrm{SEP}=0.34 \log _{10} \mathrm{cfu} / \mathrm{mL}\right)$ and $\mathrm{pH}$ (SEP $=0.031 \mathrm{pH}$ unit) were obtained from PLS-based prediction methods (5 latent variables). This technique may be applicable for predicting the shelf life and microbial loads in pasteurized milk. Further work is needed to investigate specific spoilage microorganisms and to precisely determine which biochemical changes correlate with specific SW-NIR spectral features.

\section{ACKNOWLEDGMENTS}

This research was supported in part by the International Marketing Program for Agriculture Commodities and Trade, Washington State University; Department of Nutrition and Food Technology, University of Jordan; USDA National Research Initiative Competitive Grants Program project \#2000-01617 and project \#2000-01191; and Eastern Oregon University.

\section{REFERENCES}

Al-Holy, M. A., M. Lin, A. G. Cavinato, and B. A. Rasco. 2006. The use of Fourier transform infrared spectroscopy to differentiate
Escherichia coli $\mathrm{O} 157: \mathrm{H} 7$ form other bacteria inoculated into apple juice. Food Microbiol. 23:162-168

Al-Qadiri, H. M., M. A. Al-Holy, M. Lin, N. I. Alami, A. G. Cavinato, and B. A. Rasco. 2006. Rapid detection and identification of Pseudomonas aeruginosa and Escherichia coli as pure and mixed cultures in bottled drinking water using Fourier transform infrared spectroscopy and multivariate analysis. J. Agric. Food Chem. 54:5749-5754.

Choo-Smith, L. P., K. Maquelin, T. V. Vreeswijk, H. A. Bruining, G. J. Puppels, N. A. Ngo Thi, C. Krischner, D. Naumann, D. Ami, A. M. Villa, F. Orsini, S. M. Doglia, H. Lamfarraj, G. D. Sockalingum, M. Manfait, P. Allouch, and H. P. Endtz. 2001. Investigating microbial (micro) colony heterogeneity by vibrational spectroscopy. Appl. Environ. Microbiol. 67:1461-1469.

Deeth, H. C., T. Khusniati, N. Datta, and R. B. Wallace. 2002. Spoilage patterns of skim and whole milks. J. Dairy Res. 69:227-241.

Ellis, D. I., D. Broadhurst, D. B. Kell, J. J. Rowland, and R. Goodacre. 2002. Rapid and quantitative detection of the microbial spoilage of meat by Fourier transform infrared spectroscopy and machine learning. Appl. Environ. Microbiol. 68:2822-2828.

Garbutt, J. 1997. Essentials of Food Microbiology. 1st ed. Arnold, London, UK.

Giraffa, G. 2003. Functionality of enterococci in dairy products. Int. J. Food Microbiol. 88:215-222.

Goodacre, R., E. M. Timmins, R. Burton, N. Kaderbhai, A. M. Woodward, D. B. Kell, and P. J. Rooney. 1998. Rapid identification of urinary tract infection bacteria using hyperspectral wholeorganism fingerprinting and artificial neural networks. Microbiology 144:1157-1170.

Gruetzmacher, T. J., and R. L. Bradley Jr. 1999. Identification and control of processing variables that affect the quality and safety of fluid milk. J. Food Prot. 62:625-631.

Hampton, K. A., A. G. Cavinato, D. M. Mayes, S. J. Boe, and T. L. Hoffnagle. 2001-2002. Near infrared spectroscopic classification of gender and maturity in Chinook salmon (Oncorhynchus tshawytscha). East. Oreg. Sci. J. XVII:31-36.

Hayes, W., C. H. White, and M. A. Drake. 2002. Sensory aroma characteristics of milk spoilage by Pseudomonas species. J. Food Sci. 67:448-454.

Huang, Y., A. G. Cavinato, D. M. Mayes, G. E. Bledsoe, and B. A. Rasco. 2002. Non-destructive prediction of moisture and sodium chloride in cold smoked Atlantic salmon (Salmo salar). J. Food Sci. 67:2543-2547.

Kansiz, M., P. Heraud, B. Wood, F. Burden, J. Beardall, and D. McNaughton. 1999. Fourier transform infrared microspectroscopy and chemometrics as a tool for the discrimination of cyanobacterial strains. Phytochemistry 52:407-417.

Lee, M. H., A. G. Cavinato, D. M. Mayes, and B. A. Rasco. 1992. Non-invasive short-wave-length near-infrared spectroscopic method to estimate the crude lipid content in the muscle of intact rainbow trout. J. Agric. Food Chem. 40:2176-2181.

Lin, M., M. Al-Holy, M. Mousavi-Hesary, H. Al-Qadiri, A. G. Cavinato, and B. A. Rasco. 2004. Rapid and quantitative detection of the microbial spoilage in chicken meat by diffuse reflectance spectroscopy (600-1100 nm). Lett. Appl. Microbiol. 39:148-155.

Lin, M., A. G. Cavinato, Y. Huang, and B. A. Rasco. 2003. Predicting sodium chloride content in commercial king (Oncorhynchus tshawytscha) and chum (O. keta) hot smoked salmon fillet portions by short-wavelength near-infrared (SW-NIR) spectroscopy. Food Res. Int. 36:761-766.

Lin, M., M. Mousavi, M. Al-Holy, A. Cavinato, and B. A. Rasco. 2006. Rapid near infrared spectroscopic method for the detection of spoilage in rainbow trout (Oncorhynchus mykiss) fillet. J. Food Sci. 71:18-23.

Liu, Y., B. Lyon, W. Windham, C. Realini, T. Pringle, and S. Duckett. 2003. Prediction of color, texture, and sensory characteristics of beef steaks by visible and near infrared reflectance spectroscopy. A feasibility study. Meat Sci. 65:1107-1115.

Lopez-Fandino, R., A. V. Carrascosa, and A. Olano. 1996. The effects of high pressure on whey protein denaturation and cheese-making properties of raw milk. J. Dairy Sci. 79:929-936. 
Martens, H., and T. Naes. 1989. Multivariate Calibration. John Wiley and Sons, New York, NY.

Nilsen, H., M. Esaiassen, K. Heia, and F. Sigernes. 2002. Visible/ near-infrared spectroscopy: A new tool for the evaluation of fish freshness. J. Food Sci. 67:1821-1826.

Osborne, B. G., and T. Fearn. 1986. Near-Infrared Spectroscopy in Food Analysis. Longman Sci. Technical, Wiley, New York, NY.

Oust, A., T. Moretro, C. Kirschner, J. A. Narvhus, and A. Kohler. 2004. FT-IR spectroscopy for identification of closely related lactobacilli. J. Microbiol. Methods 59:149-162.
Rodriguez-Saona, L. E., F. M. Khambaty, F. S. Fry, and E. M. Calvey. 2001. Rapid detection and identification of bacterial strains by Fourier transform near-infrared spectroscopy. J. Agric. Food Chem. 49:574-579.

Rodriguez-Saona, L. E., F. M. Khambaty, F. S. Fry, J. Dubois, and E. M. Calvey. 2004. Detection and identification of bacteria in a juice matrix with Fourier transform-near infrared spectroscopy and multivariate analysis. J. Food Prot. 67:2555-2559.

Walker, S. J. 1988. Major spoilage microorganisms in milk and dairy products. J. Soc. Dairy Technol. 41:91-92. 